\title{
Deniz seviyesi değişimlerinin belirlenmesinde GNSS-IR yönteminin kullanımı ve doğruluk analizi üzerine bir araştırma
}

\author{
Cemali Altuntaş*1(i), Nursu Tunalığlu1 \\ ${ }_{1}$ Yıldız Teknik Üniversitesi, İnşaat Fakültesi, Harita Mühendisliği Bölümü, İstanbul, Türkiye
}

\author{
Anahtar Kelimeler \\ GNSS-İnterferometrik \\ Reflektometri (GNSS-IR) \\ Deniz Seviyesi \\ Lomb-Scargle \\ Periyodogramı (LSP) \\ Sinyal-Gürültü Oranı (SNR)
}

\begin{abstract}
ÖZ
GNSS İnterferometrik Reflektometri (GNSS-IR) yöntemi, GNSS verilerinin analizi ile anten etrafındaki çevresel özelliklerin kestirimine olanak sağlamaktadır. Deniz kıyısındaki GNSS antenlerinin, deniz yüzeyinden yansıma alabilecek kadar yeterli açık görüş açısına sahip olması durumunda, GNSS-IR yöntemine dayalı olarak deniz seviyesi değişimleri belirlenebilmektedir. Bu çalıșmada, deniz seviyesi değişimlerinin GNSS-IR yöntemine dayalı olarak belirlenebilirliği, TUSAGA-Aktif ağına ait istasyonlardan Tekirdağ (TEKR) istasyonunun 2020 yllına ait bir yıllık statik GPS uydu verileri ile SNR1 ve SNR2 (L1 ve L2 frekansları) için ayrı ayrı analiz edilmiştir. Analizlerde frekans limiti, uydu yükseklik açısı limiti, spektral analiz ile elde edilen arka plan gürültü koşulu (AGK) ve medyan mutlak sapma (MAD) koșulu dikkate alınmıștır. Verilerin değerlendirilmesi için 18 farklı analiz stratejisi oluşturulmuş ve kestirimler için doğrulama verisi olarak TUDES Marmara Ereğlisi mareograf istasyonunun sağladığı deniz seviyesi ölçüleri kullanılmıştır. Sonuçlar, veriden elde edilen kestirim sayısı (KS) ve 1 yıllık veride toplam günlük kestirim kapsam sayısı bakımından da incelenmiştir. Buna göre, 1 yıllık veri için en yüksek korelasyon SNR1 ile $5^{\circ}-20^{\circ}$ yükseklik açısı ve 5AGK koşulu için \%75 (KS: 1911, Kapsam: 279) olarak bulunmuştur. Yıllık veri için en yüksek korelasyonun elde edildiği strateji ile aylık değerlendirmeler yapıldığında ise SNR1 için \%84'e, SNR2 için ise \%88'e varan korelasyon değerleri elde edilmiștir.
\end{abstract}

\section{An investigation on the use of GNSS-IR method for determining sea level changes and its accuracy analysis}

\section{Keywords}

GNSS-Interferometric

Reflectometry (GNSS-IR)

Sea Level

Lomb-Scargle Periodogram (LSP)

Signal-to-Noise Ratio (SNR)

\begin{abstract}
GNSS Interferometric Reflectometry (GNSS-IR) allows retrieving environmental characteristics around the GNSS antenna by analyzing the GNSS data. When the GNSS antenna located at the seashore has sufficient open view for receiving reflections from the sea surface, sea level changes can be determined based on the GNSS-IR method. In this study, the determinability of the sea level changes based on GNSS-IR was analyzed with 1year static GPS data dated 2020 using SNR1 and SNR2 (L1 and L2 frequencies) values of Tekirdağ station (TEKR), which is involved to CORS-TR Network. In the analyses, frequency limit, satellite elevation angle limit, background noise condition (BNC) obtained by spectral analysis and median absolute deviation (MAD) condition were considered. In order to evaluate the accuracy of the estimation results, 18 different analysis strategies were created, and sea level measurements provided by the TUDES Marmara Ereğlisi tide gauge were used as verification data. The results were also examined in terms of the number of estimates (NE) obtained from the data and the number of daily estimates coverage in 1-year data. Accordingly, the highest correlation for 1-year data was found to be $75 \%$ (NE: 1911, Coverage: 279 ) for SNR1 with $5^{\circ}-20^{\circ}$ elevation angle and 5BNC condition. When monthly evaluations were made with the strategy in which the highest correlation was obtained for the annual data, correlation values of up to $84 \%$ for SNR1 and $88 \%$ for SNR2 were obtained.
\end{abstract}




\section{Giriş}

Son yıllarda küresel iklim değişiminin meydana getirdiği ortalama deniz seviyesindeki yükselme, özellikle kıyı alanları bașta olmak üzere, bu bölgelere yakın alanlarda uzun dönemde oluşabilecek risklerin belirlenmesi, izlenmesi ve gerekli önlemlerin alınması için önem taşımaktadır. Ayrıca, özellikle küresel iklim değişikliğinin yarattığı çevresel değişimlerin izlenmesi, iklim modellerinin ve buna bağlı gelecek planlamalarının yapılmasına da katkı sağlayacaktır. Dünya nüfusunun büyük bir bölümünün kıyı alanlarında yer alması ve faaliyetlerin buralarda sürdürülmesi ise deniz kaynaklı tehlikelere karşı çalışmaların hassas yapılmasını gerektirmektedir (Neumann vd., 2015).

Farklı nedenlerle ortaya çıkan değişimlerin incelenmesinde değişik ölçme ve izleme teknikleri kullanılmaktadır. Son yıllarda, GNSS alıcılarında toplanan sinyallerin çevresel karakteristiklerin belirlenmesinde kullanılabilir olduğu kanıtlanmıștır (Wang vd., 2018). GNSS İnterferometrik Reflektometri (Interferometric Reflectometry, IR) olarak adlandırılan bu yöntem, GNSS alıcılarının tesis edildikleri yerlerin yakın çevresindeki çevresel değerlerin (zemin ile alıcı arasındaki düşey mesafe- reflektör yüksekliği-, yüzeyin yansıtıcılık özellikleri vb.) elde edilmesinde çok yolluluk sinyal yansıma özelliklerini kullanmaktadır (Larson vd., 2008, Larson vd., 2017; Small vd., 2010; Nievinski ve Larson, 2014a, 2014b; Strandberg vd., 2016, 2019). GNSS-IR tekniği, GNSS alıcısına doğrudan ve yansıyarak gelen sinyallerin oluşturduğu girişim modelini inceleyerek, yansıyan sinyallere ait parametrelerin belirlenmesine dayanmaktadır (Wang vd., 2018; Williams vd., 2020). GNSS alıcıları, anten çevresindeki yansıtıcı yüzeylerin neden olduğu çok yolluluk etkisi altındaki yansıyan sinyaller ile alıcıya doğrudan gelen sinyalleri eșzamanlı olarak anten faz merkezinde kaydetmektedir. Çok yolluluk etkisi genel olarak düşük uydu yükseklik açlarından gelen sinyallerde görülmektedir. Yüksek doğrulukta hassas konum belirleme için bir hata ve gürültü kaynağı olan yansıyan GNSS sinyalleri, alıcıda kaydedilen sinyallerin gücünde karakteristik salınımlar oluşturur. Salınım etkisinin analizi sonucunda alıcı anteni ile yansıtıcı yüzeyin arasındaki yükseklik farkı, oluşan geometrik eşitlik vasıtasıyla belirlenebilmektedir (Hofmann-Wellenhof vd., 2008).

Çok yolluluk etkisi nedeniyle alıcıda kaydedilen sinyallerin meydana getirdiği girişimin etkisi, kod, taşıyıcı faz ve sinyal gürültü oranı (Signal-to-Noise Ratio, SNR) verilerinde görülmektedir. Bunların içinden SNR, girișim yapan sinyallerde, geometrik ve radyometrik özellikler hakkında bilgi içermektedir. Sinyal gücünün gürültüye oranı olan SNR değeri, alınan sinyalin gücüyle ilişkilidir ve GNSS verilerinde yansımanın neden olduğu salınım özellikleriyle çevresel değerlerin belirlenmesinde kullanılmaktadır (Qian ve Jin, 2016; Tabibi vd., 2017). Axeldrad vd. (1996), yansiyan sinyallerin ve sinyal genliklerinin özelliklerinin belirlenmesinde SNR verilerinin kullanılabilirliğini göstermiştir.

Uydudan alıcıya yansıyarak gelen sinyaller ile yansıtıcı yüzeylere ilişkin çevresel özellikleri belirleme çalışması ilk olarak Martin-Neira (1993) tarafından gerçekleștirilmiștir. Martin-Neira (1993), alıcıda kaydedilen okyanus yüzeyinden yansıyan GPS sinyalleri ile deniz seviyesi altimetresinin belirlenebilirliğini araștırmıştır. Klasik anlamda, GPS sistemine dayalı deniz seviyesi değişimlerinin belirlenmesi, bir antenin zenit doğrultusunda diğerinin ise nadir doğrultusunda olmak üzere iki farklı anten konfigürasyonunun birlikte kullanılarak doğrudan gelen ve yansıyan sinyallerin anten faz merkezlerinde kaydedilmesine dayanmaktadır. GNSS-IR yöntemine dayalı olarak tek bir alıcı kullanılarak deniz seviyesi değișimlerinin belirlenmesine yönelik ilk çalışma, Larson vd. (2013) tarafindan gerçekleştirilmiştir. Jeodezik alıcıların sağladığı SNR verilerinde özellikle düşük uydu yükseklik açllarından $\left(5^{\circ}-25^{\circ}\right)$ gelen sinyallerde bu girișim etkisi görülmektedir. Daha yüksek uydu yükseklik açılarının da kullanılabilirliği ile ilgili bir çalıșma, Santamaría-Gómez ve Watson (2017) tarafından, bir alıcı zenit doğrultusunda diğeri ise ufuk doğrultusunda yerleștirilmek üzere iki jeodezik antenin SNR verilerinin karşılaştırılması ile yapılmıştır. $\mathrm{Bu}$ çalışmada, ufuk doğrultusunda yerleștirilen antenin daha yüksek uydu yükseklik açlarından gelen sinyaller için de girişim salınımına sahip olduğu ve deniz seviyesi değişimlerinin belirlenmesinde zenit doğrultusundaki alıcı verisinden üç kat daha hassas sonuç elde edilmesini sağladığı gösterilmiştir. Altuntaş ve Tunalıoğlu (2022), GNSS alıcı özelliklerinin ve kurulumlarının değiștirilmesinin SNR metriklerinin kestirim doğrulukları üzerindeki etkisini göstermek için, iki akıllı mobil telefonu ve iki jeodezik GNSS antenini (bir alıcı zenit doğrultusuna diğer alıcı ise ufuk doğrultusuna bakacak şekilde) yerleştirerek, eş zamanlı toplanan verileri analiz etmişlerdir. Buna göre, ufuk düzleminde toplanan sinyallerin daha yüksek uydu yükseklik açlları $\left(30^{\circ}-60^{\circ}\right)$ için de uygun kestirim değerleri ürettiği görülmüştür.

Bununla birlikte, literatürde, GNSS-IR'a dayalı kar kalınlığının/örtüsünün belirlenmesi ve etkin reflektör yüksekliğinin kestirimi (Larson vd., 2009b; Ozeki ve Heki, 2012; Gutmann vd., 2012; Chen vd., 2014; Jin vd., 2016; Tunalıoğlu vd., 2019, Altuntas ve Tunalioglu, 2021), deniz seviyesi değişimlerinin ve dalga modellerinin araştırılması (Anderson, 2000; Xi vd., 2018; Beşel ve Tanır Kayıkçı, 2021), toprak nemi ve tarımsal ürünlerin izlenmesi (Larson vd., 2008; Larson vd., 2009a; Roussel vd., 2016; Chew vd., 2016; Zhang vd., 2017; Han vd., 2020; Altuntas ve Tunalioglu, 2020) gibi pek çok çalıșma bulunmaktadır.

Temel olarak bu yöntem, çok yolluluk etkisinin, diğer bir ifadeyle anten faz merkezinde kaydedilen yansıyan sinyallerin doğrudan gelen sinyaller ile yaptığ girişim deseninin modellenmesini içermektedir. Genel anlamda klasik GNSS-IR yaklaşımı, GNSS alıcılarından sağlanan SNR verilerine ve Lomb Scargle Periyodogramı (LSP) spektral analiz yöntemine dayanmaktadır. GNSS-IR yöntemine dayalı uygulamaların yaygınlaştırılmasında ve geliştirilmesinde, yöntemde uygulanan metodolojiye bağlı olarak elde edilen kestirim değerlerinin doğruluğunun araştırılmasına, arttırılmasına ve buna bağlı sonuçların kalite kontrollerinin yapılmasına yönelik araştırmalara ihtiyaç duyulmaktadır. 
Bu çalışmada, deniz seviyesi değişimlerinin GNSS-IR yöntemine dayalı olarak belirlenebilirliğini araştırmak için, TUSAGA-AKTİ ağına ait TEKR (Tekirdağ) istasyonunun 2020 yılına ait 1 yıllık RINEX verisinden elde edilen SNR verisi; hatalı ölçü ve kestirim değerlerinin elimine edilmesi için frekans limiti, uydu yükseklik açısı limiti, arka plan gürültü koşulu (AGK) ve medyan mutlak sapma (median absolute deviation, MAD) kriterleri dikkate alınarak olușturulan 18 farklı analiz stratejisi altında değerlendirilmiştir. Çalışmada, doğrulama verisi olarak Marmara Ereğlisi mareograf istasyonundan alınan veriler kullanılmıș, aylık ve 1 yıllık korelasyon değerleri ve karesel ortalama hatalar $(\mathrm{KOH})$ hesaplanmiştır.

\section{GNSS-IR Yöntemi}

GNSS-IR yönteminde kullanılan SNR değeri, uydu yükseklik açısının bir fonksiyonudur. Uydu, alıcıya göre yükselen veya alçalan doğrultuda yörüngesindeki hareketine devam ettiği sürece yansıyan ve doğrudan gelen sinyaller alıcıda eş zamanlı olarak kaydedilir. Yöntemde, alıcıya doğrudan ve yansıyarak gelen sinyallerin meydana getirdiği girişim, uydu yükseklik açısına $(\varepsilon)$, GNSS sinyalinin dalga boyuna $(\lambda)$ ve yansıtıcı yüzey ile alıcının faz merkezi arasındaki düşey mesafeye (reflektör yüksekliği, $h$ ) bağlı periyodik bir sinyal meydana getirir. Uzun periyotlarda SNR verisi üzerinde bu sinyal girişimi, karakteristik bir salınım meydana getirir. Oluşan bu sinyal Eşitlik 1'de verildiği gibi modellenebilmektedir.

$S N R=A_{d}+A \cos \left(\frac{4 \pi h}{\lambda} \sin \varepsilon+\phi\right)$

Burada, $A_{d}$ doğrudan gelen sinyalin genliği, $A$ yansıyan sinyalin genliği, $\phi$ faz ofsetidir. Eşitlik 1'de doğrudan gelen sinyalin etkisini elimine etmek için, düșük dereceli polinom SNR verisine uygulanıp bu trend veriden çıkarılırsa geriye kalan trendden arındırılmış veri Eşitlik 2'de verildiği gibi bulunur (Larson vd., 2013):

$\delta S N R=A \cos \left(\frac{4 \pi h}{\lambda} \sin \varepsilon+\phi\right)$

$\delta S N R$ verisi üzerinde baskın frekans $f=2 h / \lambda$ eşitliği ile ilişkilidir. Burada, çok yolluluk etkisine sahip sinyalin baskın frekansı hesaplanırsa, $h$ değeri hesaplanabilmektedir. $\delta S N R$ verisi, düzenli bir aralık değerine sahip olmayıp uydu yükseklik açısının sinüsüne bağlı bir aralık değer ile temsil edildiğinden düzensiz örneklenmekte, bu nedenle baskın frekansın hesaplanmasında, LSP kullanilmaktadır (Lomb, 1976; Scargle, 1982). Periyodogram üzerinden, her bir uydu geçişi için $\delta S N R$ verisine ait hesaplanan frekans değerleri, $h=f \lambda / 2$ ilişkisi kullanılarak deniz yüzeyinden alıcl faz merkezine olan düșey mesafeye (reflektör yüksekliği) dönüştürülür.

\section{Uygulama}

\subsection{Test alanı}

Test alanı olarak Marmara Denizi kıyısında yer alan Tekirdağ ili sahil kesimi seçilmiştir. Bu amaçla ülkemizde ulusal düzeyde sıklıkla Ağ-RTK uygulamaları için kullanılan TUSAGA-AKTİF ağına ait TEKR isimli referans istasyonunun 2020 yılına ait 30 saniye veri kayıt aralıklı, 24 saatlik 1 yıllık RINEX formatındaki gözlem verileri kullanılmıştır. TEKR istasyonu, Marmara Bölgesi'nde Tekirdağ ili sınırları içinde, deniz kenarındaki bir yapının terasında yer almaktadır. Gerçekleştirilen analizler sonucunda, TEKR istasyonu verileri kullanılarak GNSS-IR yöntemi ile yapılan kestirimlerin doğrulaması, Harita Genel Müdürlügü (HGM) yetki ve sorumluluğunda olan Türkiye Ulusal Deniz Seviyesi İzleme Sistemi (TUDES) ağında yer alan Marmara Ereğlisi mareograf istasyonunun sağladığı deniz seviyesi ölçüleri ile yapılmıştır (Şekil 1). İstasyonlara ilişkin bilgiler Tablo 1 'de verilmiştir. İki istasyon arasındaki mesafe yaklaşık 40 km'dir.

\subsection{Verilerin değerlendirilmesi ve analizi}

$\mathrm{Bu}$ çalışmada TEKR istasyonunda 2020 yılı boyunca toplanan 1 yıllık statik GNSS gözlemleri ve Marmara Ereğlisi mareograf istasyonu tarafından sağlanan deniz seviyesi ölçülerinin günlük ortalamaları kullanılmıștır. GNSS gözlemlerinden yalnızca GPS uyduları için sağlanan veriler kullanılmış, L1 SNR (SNR1) ve L2 SNR (SNR2) verileri değerlendirilmiştir.

GNSS-IR çalışmalarında verinin azimut ve yükseklik açıları yönünden filtrelemeye tabi tutulması önemlidir. Yükseklik açısı sınır değerleri genellikle yansımanın fazla olduğu düşük yükseklik açılarını içerecek şekilde belirlenir. Azimut sınır değerleri ise, istasyon konumuna bağlı olarak çevreleyen alan özellikleri dikkate alınarak seçilir.

$\mathrm{Bu}$ çalışma kapsamında değerlendirilecek verinin deniz yüzeyinden olan yansımaları içermesi dikkate alınmıștır. $\mathrm{Bu}$ nedenle, öncelikle TEKR istasyonunun denize olan mesafesi ve azimut değerleri irdelenmiştir. İstasyon ile yansıma yüzeyi arasındaki mesafe, $50^{\circ}$ azimut yönünde yaklașık $100 \mathrm{~m}$ iken, $60^{\circ}$ 'de yaklașık 80 m, 80de yaklaşık 55 m, 100' de yaklaşık 40 m, 120'de yaklaşık $35 \mathrm{~m}, 140^{\circ}$ de yaklaşık $40 \mathrm{~m}, 190^{\circ} \mathrm{de}$ ise yaklașık 100 m'dir (Tablo 2).

TEKR istasyonunun deniz seviyesinden olan yüksekliği yaklaşık 10 m'dir. GNSS alıcısına yansıyarak gelen sinyalin yansıma yaptığı noktanın konumu, bu yükseklik değerine ve uydu yükseklik açısına bağlı olarak belirlenebilmektedir. Buna göre, $10 \mathrm{~m}$ reflektör yüksekliğine sahip TEKR istasyonunun yansıma noktalarına olan mesafesi uydu yükseklik açısına bağlı olarak Tablo 3'te verildiği şekilde değişim göstermektedir.

Tablo 1. İstasyonlara ilişkin konum (WGS 84) ve kayıt bilgileri

\begin{tabular}{|c|c|c|c|}
\hline$\sum_{\mathcal{G}}^{\infty}$ & TEKR & $\begin{array}{l}\text { Enlem } \\
\text { Boylam } \\
\text { Veri kayıt } \\
\text { aralığı } \\
\end{array}$ & $\begin{array}{l}40^{\circ} 57^{\prime} 30.00^{\prime \prime} \mathrm{K} \\
27^{\circ} 29^{\prime} 47.39^{\prime \prime} \mathrm{D} \\
30 \mathrm{sn}\end{array}$ \\
\hline 范 & $\begin{array}{c}\text { MARMARA } \\
\text { EREĞLİSİ }\end{array}$ & $\begin{array}{l}\text { Enlem } \\
\text { Boylam } \\
\text { Gözlem } \\
\text { sıklı̆̆ }\end{array}$ & $\begin{array}{l}40^{\circ} 58^{\prime} 08.28^{\prime \prime} \mathrm{K} \\
27^{\circ} 57^{\prime} 43.75^{\prime \prime} \mathrm{D} \\
15 \mathrm{dk}\end{array}$ \\
\hline
\end{tabular}




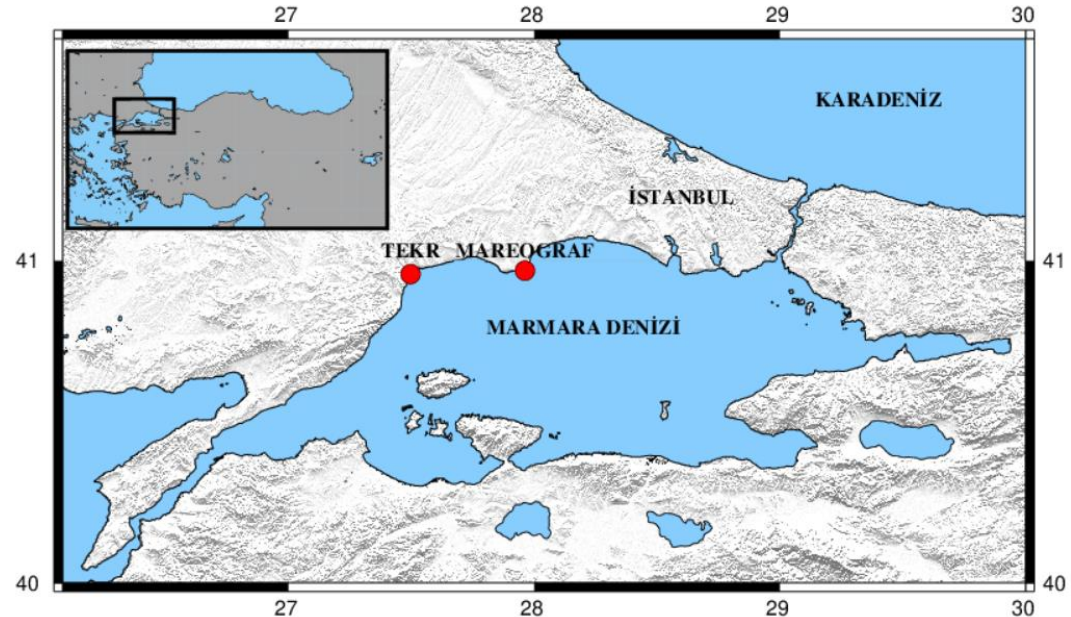

(a)

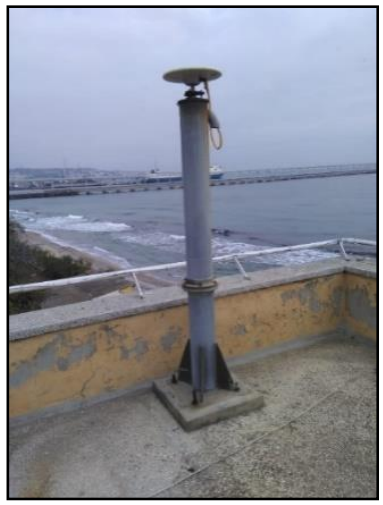

(b)

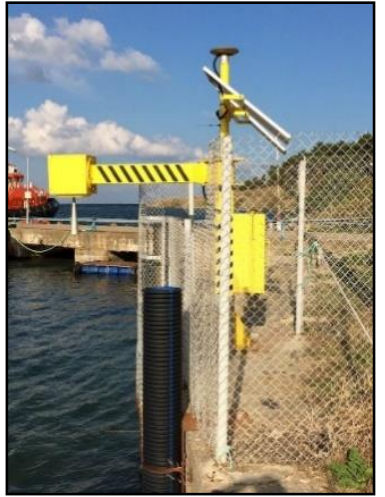

(c)

Şekil 1. (a) Test alanı ve istasyonların konumları, (b) TEKR sabit GNSS istasyonu (c) Marmara Ereğlisi mareograf istasyonu

Tablo 2. TEKR istasyonunun denize olan mesafesinin azimuta göre değișimi

\begin{tabular}{lccccccccc}
\hline Azimut $\left({ }^{\circ}\right)$ & 50 & 60 & 80 & 100 & 120 & 140 & 160 & 180 & 190 \\
Denize olan mesafe (m) & $\sim 100$ & $\sim 80$ & $\sim 55$ & $\sim 40$ & $\sim 35$ & $\sim 40$ & $\sim 45$ & $\sim 70$ & $\sim 100$
\end{tabular}

Tablo 3. TEKR istasyonunun yansıma noktasına olan mesafesinin uydu yükseklik açısına göre değișimi

\begin{tabular}{|c|c|c|c|c|c|c|c|c|c|c|c|c|c|c|c|c|}
\hline $\begin{array}{l}\text { Uydu yükseklik } \\
\left.\text { açısı ( }{ }^{\circ}\right)\end{array}$ & 5 & 6 & 7 & 8 & 9 & 10 & 11 & 12 & 13 & 14 & 15 & 16 & 17 & 18 & 19 & 20 \\
\hline $\begin{array}{l}\text { Yansıma } \\
\text { noktasına mesafe } \\
\text { (m) }\end{array}$ & 114 & 95 & 81 & 71 & 63 & 56 & 51 & 47 & 43 & 40 & 37 & 36 & 34 & 32 & 31 & 29 \\
\hline
\end{tabular}

Tablo 2 ve Tablo 3'teki değerler incelendiğinde teorik olarak yansımaların deniz yüzeyinden gelebilmesi için uygun olan açı aralıkları uydu yükseklik açısı için $5^{\circ}-10^{\circ}$, buna bağlı olarak azimut açısı için ise $80^{\circ}-170^{\circ}$ olmaktadır. $\mathrm{Bu}$ aralıklar, yansıma noktalarının deniz yüzeyinde yer alması gerekliliği dikkate alınarak belirlenmiștir $\left(5^{\circ}-10^{\circ}\right.$ uydu yükseklik açısı aralığı için yansıma noktasına olan mesafe en az $\sim 56$ m olmaktadır. Denize olan mesafenin 56 m'den daha düşük olduğu aralık ise $80^{\circ}-170^{\circ}$ azimut aralığıdır). Fakat deniz yüzeyi düz bir arazi yüzeyi gibi pürüzsüz ve durağan değildir. Dalgalı ve zamana bağlı olarak değişen bir yüzey yapısına sahiptir. Bu durum dikkate alındığında, deniz yüzeyinden olan gerçek yansıma açısının hesaplanan bu değerlerden farklı olabileceği düşünülmektedir. Bu nedenle $5^{\circ}-10^{\circ}$ uydu yükseklik açısı aralığına $5^{\circ}-15^{\circ}$ ve $5^{\circ}-20^{\circ}$ aralıkları da ilave edilmiştir. Azimut aralığı ise $80^{\circ}-170^{\circ}$ olacak şekilde sabit alınmıştır.

Uydu yükseklik açısı ve azimut aralığı koşullarını sağlayan SNR verileri alçalan ve yükselen uydu geçişleri için gruplandırılmış, her bir uydu geçişine ait SNR veri setleri belirlenmiştir. TEKR istasyonu çatı terasında yer aldığı ve teras yüzeyinden gelen yansımaları da almış olduğu için SNR verisi üzerinde düşük frekanslı bir bileşenin de mevcut olduğu görülmüştür. SNR verisinin trendinin ve bu düşük frekanslı bileşenin birlikte giderilmesi için 5 . dereceden bir polinom kullanılmıştır. Her bir $\delta S N R$ veri setinin frekansının bulunması için LSP 
kullanılmıştır. LSP ile her bir frekansa karşılık gelen spektral genlik değeri hesaplanmaktadır. Spektral genliği maksimum olan frekans değeri, $\delta S N R$ verisinin baskın frekansı olarak kabul edilmektedir. Fakat bu maksimum spektral genlik (pik) değeri her zaman baskın frekansa karşıllk gelmemektedir. Bu nedenle kestirimlere ilk olarak minimum-maksimum frekans limiti uygulanarak sınır değerlerin dışında kalan kestirimler atılmıştır. SNR1 verileri için bu limit 100-120 olarak ayarlanırken, SNR2 verileri için 80-100 olarak ayarlanmıştır. Bu frekans aralıkları uzunluk türünden sırasıyla $\sim 4 \mathrm{~m}$ ve $\sim 5$ m'ye karşılık gelmektedir. İstasyondaki yıllık deniz seviyesi değişiminin maksimum $1 \mathrm{~m}$ seviyelerinde olduğu dikkate alındığında bu frekans aralıklarının kaba hatalı kestirimlerin giderilmesi için ön bir adım olarak uygulanmasının uygun olduğu görülmüștür. Bunun dışında, literatürdeki çalışmalarda pik genliğinin, arka plan gürültüsü olarak adlandırılan ortalama genlik değerine bölünmesiyle bulunan bir oran (AGK) üzerinden kestirimlere ilişkin kalite kontrolü yapılmaktadır. Söz konusu oranın belirlenen bir sayıdan büyük olması durumunda kestirilen frekans değeri efektif kabul edilmektedir. Bu çalışmada, AGK için uygulanacak katsayılar 3,4 ve 5 olarak belirlenmiştir. AGK, LSP ile bulunan spektral genlik değerleri $\left(\mathbf{A}_{\mathrm{LSP}}\right)$ kullanılarak, Eşitlik 3 ile hesaplanmıştır:

$$
A G K=\frac{\operatorname{maksimum}\left(\mathbf{A}_{\mathbf{L S P}}\right)}{\operatorname{ortalama}\left(\mathbf{A}_{\mathbf{L S P}}\right)}
$$

AGK ile hatalı kestirimler büyük oranda giderilse de bazı durumlarda ek bir ölçüt kullanımına ihtiyaç duyulmaktadır. Bu çalıșmada, MAD koșulu 1 katsayısıyla uygulanmıştır. MAD değeri, Eşitlik 4 vasıtasıyla hesaplanmıştır (Rousseeuw ve Leroy, 1987):

Burada; $\mathbf{h}$ ile GNSS-IR ile yapılan reflektör yüksekliği kestirimleri, med(h) ile kestirimlerin ortanca değeri ifade edilmektedir. Tüm büyüklükler metre birimindedir. Alıcının sağladığı SNR verisinden reflektör yüksekliğinin kestirimine kadar izlenen işlem adımları Şekil 2'de verilmiştir.

Tüm durumlar dikkate alındığında, toplamda 18 farklı analiz stratejisi (AS) ile değerlendirme yapılmıștır (Tablo 4).

$$
M A D=\left\{\begin{array}{c}
1.2533 \times \frac{1}{n} \times \sum|\mathbf{h}-\operatorname{med}(\mathbf{h})|, \operatorname{med}|\mathbf{h}-\operatorname{med}(\mathbf{h})|=0, \\
1.4826 \times \operatorname{med}|\mathbf{h}-\operatorname{med}(\mathbf{h})|, \operatorname{med}|\mathbf{h}-\operatorname{med}(\mathbf{h})| \neq 0,
\end{array}\right.
$$

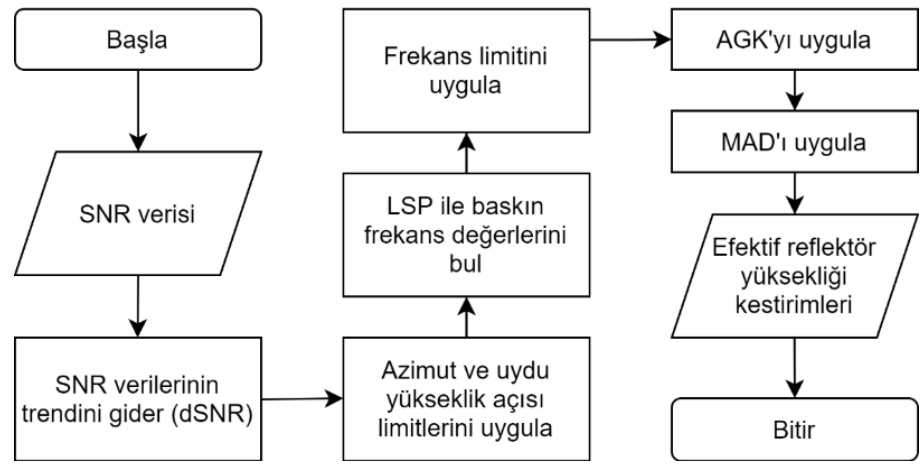

Şekil 2. SNR verisinden reflektör yüksekliği kestirimi için izlenen iş akış diyagramı

Tablo 4. Analiz stratejileri (UYAA: Uydu yükseklik açısı aralığı)

\begin{tabular}{cccc}
\hline \#AS & UYAA $\left(^{\circ}\right)$ & AGK & MAD \\
\hline AS01 & $5-10$ & 3 & - \\
AS02 & $5-15$ & 3 & - \\
AS03 & $5-20$ & 3 & - \\
AS04 & $5-10$ & 4 & - \\
AS05 & $5-15$ & 4 & - \\
AS06 & $5-20$ & 4 & - \\
AS07 & $5-10$ & 5 & - \\
AS08 & $5-15$ & 5 & - \\
AS09 & $5-20$ & 5 & - \\
AS10 & $5-10$ & 3 & 1 \\
AS11 & $5-15$ & 3 & 1 \\
AS12 & $5-20$ & 3 & 1 \\
AS13 & $5-10$ & 4 & 1 \\
AS14 & $5-15$ & 4 & 1 \\
AS15 & $5-20$ & 4 & 1 \\
AS16 & $5-10$ & 5 & 1 \\
AS17 & $5-15$ & 5 & 1 \\
AS18 & $5-20$ & 5 & 1 \\
\hline
\end{tabular}


Farklı analiz stratejileri için yapılan GNSS-IR reflektör yüksekliği kestirimlerini deniz seviyesi ölçüleriyle kıyaslayabilmek için aşağıda sıralanan metodoloji izlenmiștir:

(1) Mareograf istasyonunun 1 Ocak 2020 tarihi için sağladığı deniz seviyesi verisinin ortalaması ilk günün deniz seviyesi ölçüm değeri olarak kaydedilmiştir $\left(D S_{\text {mare }, 1}\right)$.

(2) GNSS-IR ile 1 Ocak 2020 tarihi için yapılan reflektör yüksekliği kestirimlerinin ortalaması ilk günün reflektör yüksekliği kestirimi olarak kaydedilmiștir $\left(R H_{1}\right)$.

(3) Tüm günler için yapılan reflektör yüksekliği kestirimleri $\left(R H_{i}\right), R H_{1}$ 'den çıarılarak yükseklik farkları bulunmuştur $\left(\triangle R H_{i}\right)$.

(4) Her bir gün için GNSS-IR tekniğiyle yapılan deniz seviyesi kestirimleri $D S_{\text {mare, } 1}$ ile $\Delta R H_{i}$ değerleri toplanarak bulunmuștur $\left(D S_{G I R, i}\right)$.

Son adımda belirtilen durum Eşitlik 5'te gösterilmektedir:

$D S_{G I R, i}=D S_{\text {mare }, 1}+\Delta R H_{i}$
Burada; $D S_{G I R, i}:$ GNSS-IR deniz seviyesi kestirim değerini, $D S_{\text {mare }, 1}$ : ilk gün için mareograf istasyonundan sağlanan deniz seviyesi değerini, $\Delta R H_{i}: 1$. gün ile $i$. gün arasındaki GNSS-IR reflektör yüksekliği kestirim değerleri farkını ifade etmektedir. Verilen eşitlikteki tüm büyüklükler metre birimindedir.

\section{Bulgular ve tartışma}

Yapılan analizler sonucunda elde edilen korelasyon, $\mathrm{KOH}$, kestirim sayısı (KS) ve kapsam (kestirim yapılan gün sayısı) değerleri Tablo 5 'te verilmiştir. KOH değerleri Eşitlik 6 kullanılarak hesaplanmıştır:

$K O H=\sqrt{\frac{\sum_{i=1}^{N}\left(D S_{G I R, i}-D S_{\text {mare }, i}\right)^{2}}{N}}$

Burada; $D S_{G I R, i}: i$. gün için GNSS-IR deniz seviyesi kestirim değerini, $D S_{\text {mare }, i}$ : $i$. gün için mareograf istasyonundan sağlanan deniz seviyesi ölçüm değerini, $N$ ise gün sayısını ifade etmektedir.

Tablo 5. SNR1 ve SNR2 verilerinin 18 farklı stratejiyle yapılan analiz sonuçları

\begin{tabular}{lcccccccc}
\hline & \multicolumn{3}{c}{ SNR1 } & \multicolumn{5}{c}{ SNR2 } \\
\hline & \multirow{2}{*}{ Korelasyon } & $\begin{array}{c}\text { KOH } \\
\text { (cm) }\end{array}$ & KS & $\begin{array}{c}\text { Kapsam } \\
\text { (gün) }\end{array}$ & Korelasyon & $\begin{array}{c}\text { KOH } \\
\text { (cm) }\end{array}$ & KS & $\begin{array}{c}\text { Kapsam } \\
\text { (gün) }\end{array}$ \\
\cline { 2 - 9 } AS01 & 0.58 & 18.0 & 4270 & 361 & 0.42 & 13.5 & 5202 & 363 \\
AS02 & 0.54 & 12.5 & 5056 & 359 & 0.67 & 8.5 & 7094 & 364 \\
AS03 & 0.61 & 10.7 & 5792 & 360 & 0.69 & 7.9 & 7448 & 364 \\
AS04 & 0.58 & 14.8 & 1780 & 321 & 0.39 & 29.8 & 1426 & 318 \\
AS05 & 0.63 & 11.3 & 2920 & 320 & 0.68 & 8.5 & 5212 & 355 \\
AS06 & 0.60 & 11.0 & 4069 & 332 & 0.68 & 8.6 & 6026 & 361 \\
AS07 & 0.40 & 31.1 & 276 & 156 & 0.28 & 18.7 & 69 & 54 \\
AS08 & 0.61 & 12.8 & 1093 & 253 & 0.72 & 8.4 & 2783 & 323 \\
AS09 & 0.75 & 10.8 & 1911 & 279 & 0.71 & 7.8 & 4148 & 343 \\
AS10 & 0.52 & 18.6 & 2966 & 361 & 0.37 & 15.2 & 3555 & 363 \\
AS11 & 0.53 & 12.8 & 3397 & 359 & 0.62 & 9.3 & 4765 & 364 \\
AS12 & 0.59 & 11.1 & 3862 & 360 & 0.66 & 8.5 & 4968 & 364 \\
AS13 & 0.55 & 17.8 & 1292 & 321 & 0.38 & 30.6 & 1042 & 318 \\
AS14 & 0.62 & 11.7 & 1981 & 320 & 0.65 & 9.0 & 3549 & 355 \\
AS15 & 0.59 & 11.3 & 2761 & 332 & 0.65 & 9.0 & 4111 & 361 \\
AS16 & 0.39 & 31.2 & 246 & 156 & 0.28 & 18.8 & 65 & 53 \\
AS17 & 0.57 & 12.8 & 802 & 253 & 0.70 & 8.9 & 1925 & 323 \\
AS18 & 0.73 & 11.7 & 1318 & 279 & 0.69 & 8.0 & 2859 & 342 \\
\hline
\end{tabular}

Tablo 5'te yer alan sonuçlara göre SNR1 ile yapılan kestirimlerde en yüksek korelasyon değeri AS09 stratejisi ile 0.75 olarak elde edilmiştir. En düşük $\mathrm{KOH}$ değeri ise AS03 stratejisiyle $10.7 \mathrm{~cm}$ olarak elde edilmiștir. Fakat bu stratejide korelasyon değeri 0.61 'dir. Bununla beraber en yüksek korelasyonun elde edildiği AS09 stratejisinin $\mathrm{KOH}$ değeri de $10.8 \mathrm{~cm}$ olduğundan $\mathrm{KOH}$ yönünden AS03 kadar iyi bir sonuç sağladığı görülmektedir. Bu durumda, SNR1 ile en iyi sonuçlar AS09 stratejisiyle elde edilmiştir. AS09 ile yapılan analizler sonucunda 2020 yllının 366 gününün 279'u için deniz seviyesi kestirimi yapılabilmiştir. 279 adet günlük kestirim değeri toplam 1911 adet kestirim kullanılarak hesaplanmıştır.
SNR2 verisiyle yapılan kestirimlerde en yüksek korelasyon değerinin AS08 ile 0.72 olarak elde edildiği görülmüștür. En düşük KOH değeri ise AS09 ile $7.8 \mathrm{~cm}$ olarak bulunmuştur. Fakat SNR2 kestirimlerinde korelasyon ve $\mathrm{KOH}$ yönünden öne çıan tek bir strateji olmadığı görülmektedir. Burada, bazı stratejilerin korelasyon ve $\mathrm{KOH}$ değerleri birbirlerine çok yakındır. Örneğin AS08'in korelasyon değeri 0.72 iken, AS09'un korelasyon değeri 0.71 'dir. Bu iki stratejinin $\mathrm{KOH}$ değerleri ise sırasıyla $8.4 \mathrm{~cm}$ ve $7.8 \mathrm{~cm}$ 'dir. Yine aynı iki stratejinin kestirim sayıları sırasıyla 2783 ve 4148 iken, kapsamlarının da 323 gün ve 343 gün olduğu görülmektedir. Burada, iki strateji arasındaki korelasyon farkının küçük olması ve diğer ölçütler $(\mathrm{KOH}, \mathrm{KS}$, 
kapsam) yönünden daha iyi sonuçlar sağlıyor olması nedeniyle AS09 stratejisi, SNR2 verileri için de en uygun strateji olarak öne çlkmaktadır. Bununla beraber 0.69'luk korelasyon, 7.9 cm'lik KOH, 7448'lik kestirim sayısı ve 364 günlük kapsam değerleri veren AS03 stratejisinin de kullanılabilirliği görülmektedir.

SNR1 ve SNR2 sonuçları genel olarak incelendiğinde dikkat çeken ilk husus, uydu yükseklik açısı aralığı $5^{\circ}-10^{\circ}$ olarak kullanıldığında SNR verisinin iyi kestirimler yapabilmek için yetersiz kaldığıdır (Şekil 3). SNR1 sonuçlarında $5^{\circ}-15^{\circ}$ yerine $5^{\circ}-20^{\circ}$ aralığının kullanıldığ durumlarda da kestirimler dört ölçüt yönünden de iyileşmiştir. SNR2 sonuçlarında ise bu iyileşme, korelasyon ve $\mathrm{KOH}$ yönünden düşük olurken, daha çok kestirim sayısı ve kapsam ölçütlerinde gerçekleşmiştir. Buna göre, TEKR istasyonunda GNSS-IR analizlerinde $5^{\circ}$ $20^{\circ}$ uydu yükseklik açısı aralığını kullanmanın uygun olduğu görülmektedir. Bunun dișında, mevcut koșullara ek olarak MAD koşulunun uygulanmasının sonuçları iyileştirmediği görülmüştür.
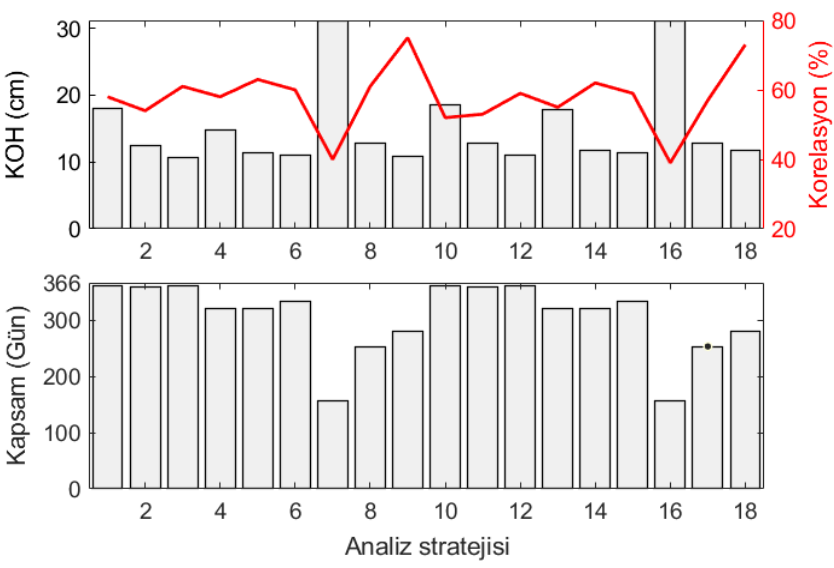

(a)
Şekil 4'te AS09 stratejisi izlenerek yapılan deniz seviyesi kestirimleri gösterilmiștir. Hem SNR1 hem de SNR2 ile yapılan kestirimlerde yıllık korelasyon değeri 0.70 'in üzerinde hesaplanmıș olsa da, grafik üzerinde bazı dönemlerde yüksek hataların ve düşük korelasyonun olduğu görülmektedir. $\mathrm{Bu}$ durumun incelenmesi için aylık korelasyon ve $\mathrm{KOH}$ değerleri hesaplanmıș, sonuçlar Şekil 5'te gösterilmiștir. Şekil 5 'teki grafik çiftlerinde üst grafikler GNSS-IR deniz seviyesi kestirimleriyle mareograf istasyonu ölçülerini gösterirken, alt grafik günlük GNSS-IR kestirimi ile günlük mareograf istasyonu ölçümü arasındaki farkları (hataları) göstermektedir.

Şekil 5'e bakıldığında SNR1 verileri ile 0.84'e, SNR2 verileri ile 0.88 'e varan aylık korelasyon değerleri olduğu görülmektedir. Ayrıca, en düșük KOH değerleri bakımından incelendiğinde, farklı aylık periyotlarda olmakla birlikte SNR1 için $4.5 \mathrm{~cm}$, SNR2 için $4.0 \mathrm{~cm}$ civarında hatalar bulunmuştur.
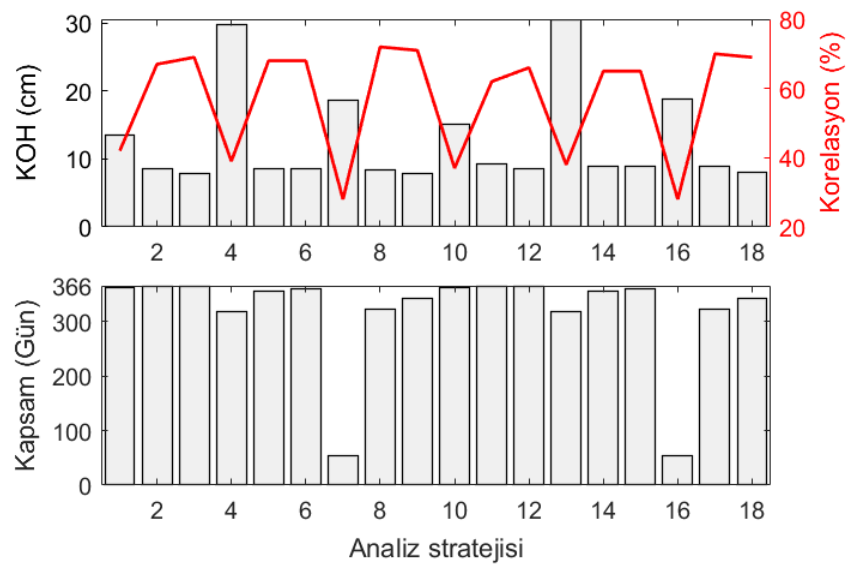

(b)

Şekil 3. Korelasyon, KOH ve kapsam değerleri (a) SNR1 analiz sonuçları (b) SNR2 analiz sonuçları

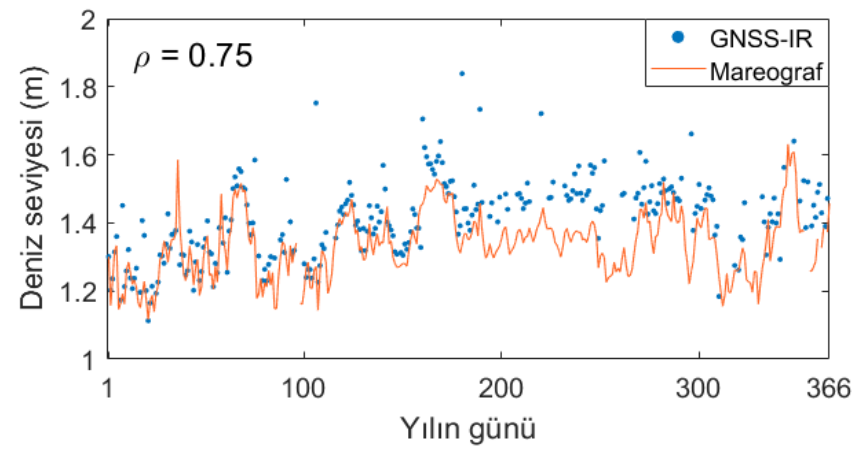

(a)

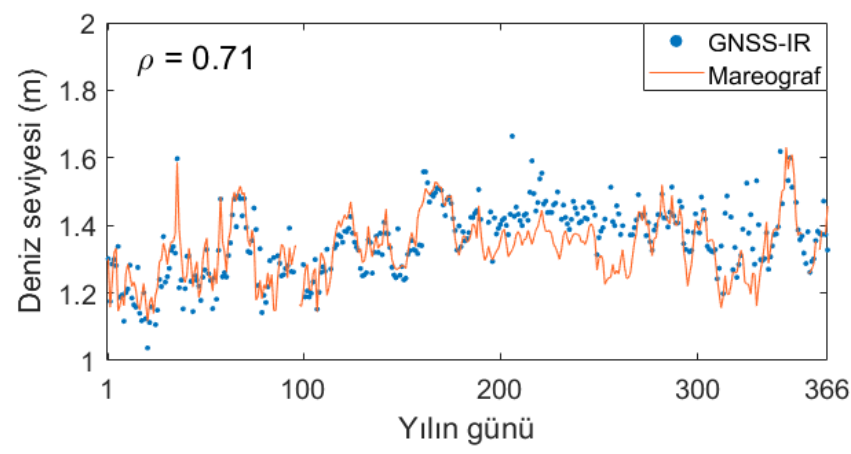

(b)

Şekil 4. AS09 stratejisiyle yapılan deniz seviyesi kestirimleri (a) SNR1 kestirimleri (b) SNR2 kestirimleri 

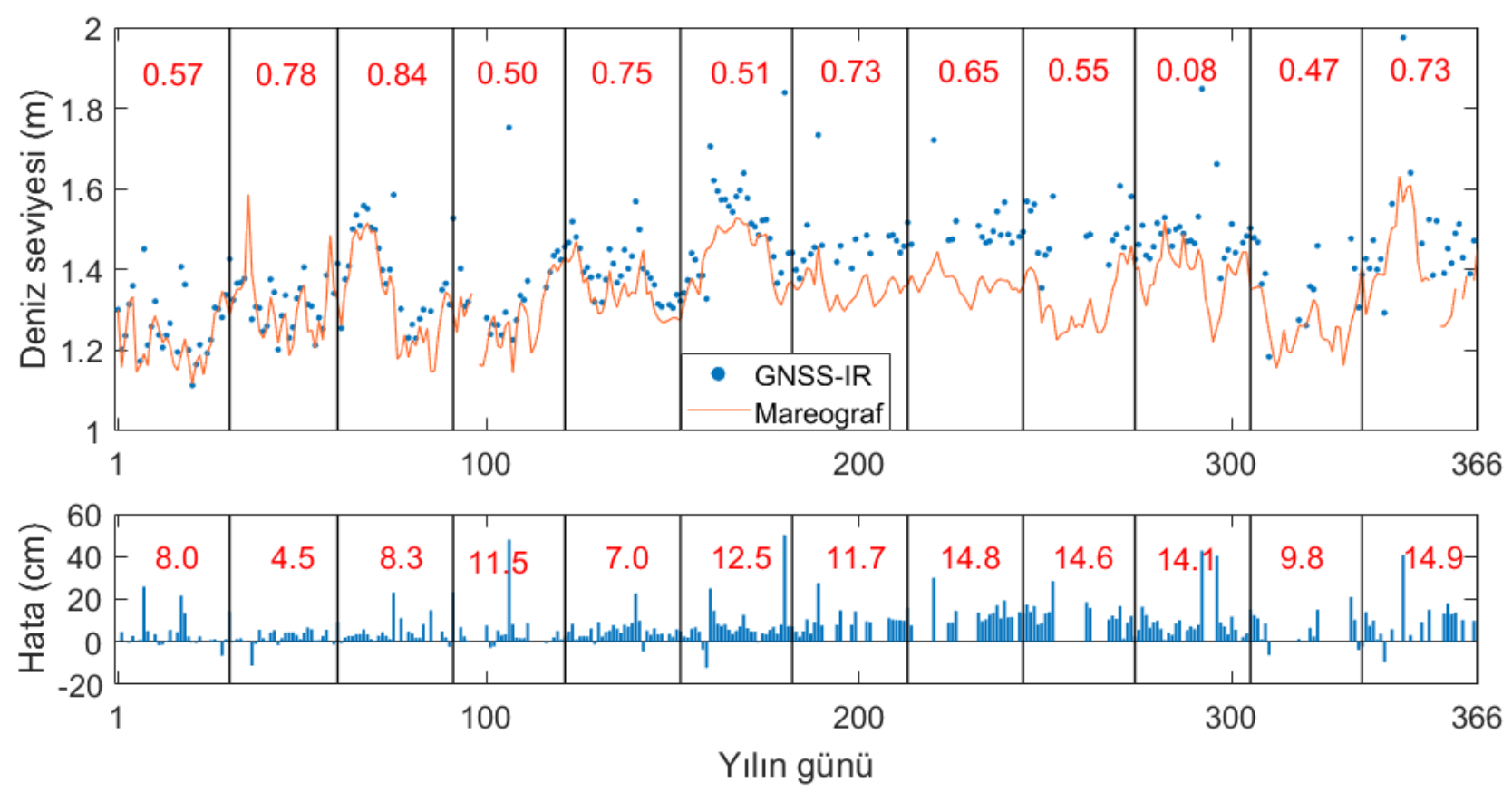

(a)
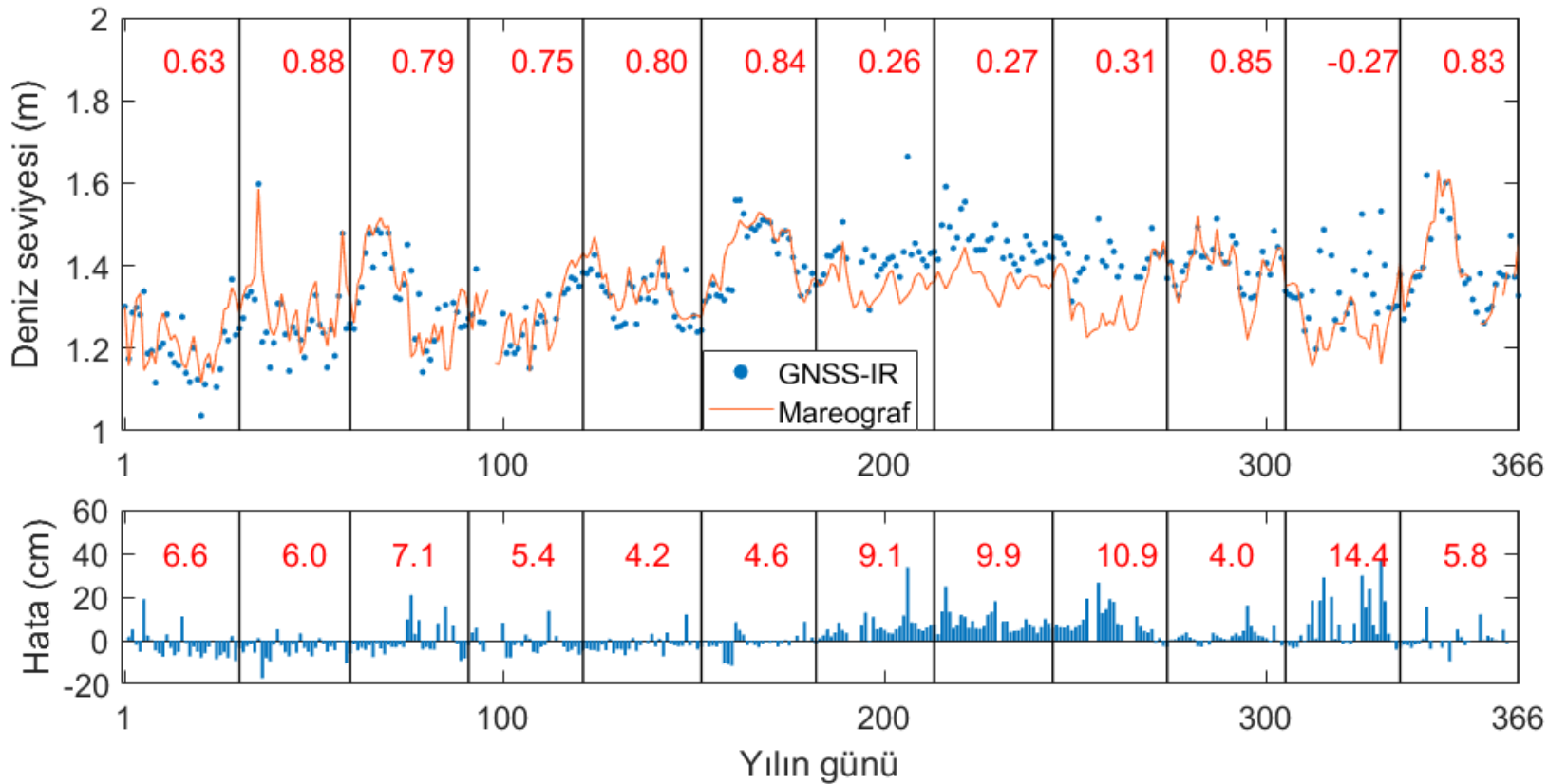

(b)

Şekil 5. AS09 stratejisiyle yapılan deniz seviyesi kestirimleri (aylık sonuçlar) (a) SNR1 kestirimleri (b) SNR2 kestirimleri (Deniz seviyesi grafiklerindeki kırmızı sayılar aylık korelasyon değerlerini gösterirken, hata grafiklerindeki kırmızı sayılar aylık KOH değerlerini göstermektedir).

\section{Sonuç}

Deniz seviyesi değişimlerinin uzun periyotlarda izlenmesi ve izlenen değerlerin iklim modellerinde kullanılması, okyanuslar ve diğer su kütleleri bașta olmak üzere atmosferik çalışmalar, karasal alanlar, kar ve buzullar gibi küresel iklim değișiminin etkilediği tüm bileșenler ile dikkatle incelenip irdelenmesi gereken önemli bir konudur. Özellikle küresel iklim değişikliğinin yarattığı çevresel değişimlerin izlenmesi son yıllarda yoğun olarak araștırlan bir alan haline gelmiştir. Son yıllarda, GNSS-IR adı verilen yöntem, GNSS alıcısında toplanan sinyallerin analizi ile çevresel parametrelerin kestirilmesine olanak sağlamaktadır. GNSS alıcılarından sağlanan SNR verilerinin kullanıldığı GNSS-IR yöntemi, denize yakın ve yeterli açı görüşe sahip istasyonlarda uygulandığında, deniz seviyesi değişimlerinin de izlenebilmesine olanak sağlamaktadır.

$\mathrm{Bu}$ çalışmada, Türkiye kıyılarında deniz seviyesi değişimlerinin GNSS-IR yöntemine dayalı olarak belirlenebilirliğini araştırmak için Marmara Denizi kıyısında bulunan TEKR istasyonuna ait 1 yllık GPS gözlem verisi kullanılmıştır. Dört farklı kriter altında, oluşturulan 18 senaryoya göre istasyon konumu da dikkate alınarak, deniz seviyesi değişimleri belirlenmiş, elde edilen sonuçlar Marmara Ereğlisi mareograf istasyonunun aynı zaman aralı̆ında tanımlı deniz seviyesi değişim verileri ile karşılaştırılmıştır. Gerçekleștirilen analizlerde, TEKR istasyonunun deniz yüzeyindeki yansıma noktası başta olmak üzere, uydu 
yükseklik açısı aralık değeri ve buna bağlı olarak kestirimde izlenecek metodolojinin önemi bu çalışmada kapsamlı bir șekilde irdelenmiștir. Çalıșmada verisi kullanilan TEKR istasyonunun anteni zenit doğrultusunda yerleștirilmiş jeodezik bir antendir. Literatür incelendiğinde, konu ile ilgili araștırma çalışmalarının yoğun olarak devam ettiği ve yeni yaklaşımların araştırıldığı görülmektedir. Bununla birlikte, literatürde alıcı kurulum konfigürasyonunun değiştirilmesi ile daha sağlıklı ve hassas sonuçların elde edilebileceğini gösteren çalışmalar da bulunmaktadır.

$\mathrm{Bu}$ çalışmadan elde edilen sonuçlar göstermiştir ki, GNSS referans istasyonu konum ve kurulum özellikleri irdelenerek Türkiye kıyılarındaki istasyon altyapıları kullanılarak deniz seviyesi değişimleri ulusal boyutta GNSS-IR yöntemi ile alternatif olarak izlenebilir.

\section{Bilgilendirme/Teşekkür}

Çalışma kapsamında kullanılan GNSS verilerini sağlayan Tapu ve Kadastro Genel Müdürlüğü'ne (TKGM), mareograf istasyonu verileri sağlayan Harita Genel Müdürlüğü'ne (HGM) teşekkür ederiz.

\section{Araştırmacıların katkı oranı}

Cemali Altuntaş: Fikir, Analiz ve yorumlama, Makale yazma, Görselleştirme. Nursu Tunalıoğlu: Fikir, Analiz ve yorumlama, Makale yazma ve düzenleme.

\section{Çatışma beyanı}

Herhangi bir çıkar çatışması bulunmamaktadır.

\section{Kaynakça}

Altuntas C \& Tunalioglu N (2020). Estimation performance of soil moisture with GPS-IR method. Sigma Journal of Engineering and Natural Sciences, 38(4), 2217-2230.

Altuntas C \& Tunalioglu N (2021). Feasibility of retrieving effective reflector height using GNSS-IR from a single-frequency android smartphone SNR data. Digital Signal Processing, 112(2021), 103011.

Altuntaş C \&Tunalıoğlu N (2022). Retrieving the SNR metrics with different antenna configurations for GNSS-IR. Turkish Journal of Engineering, 6(1), 87-94. DOI: $10.31127 /$ tuje.870620

Anderson K D (2000). Determination of water level and tides using interferometric observations of GPS signals. Journal of Atmospheric and Oceanic Technology, 17(8), 1118-1127, doi:10.1175/15200426(2000)017<1118:DOWLAT>2.0.CO;2.

Axelrad P, Comp C J \& Macdoran P F (1996). SNR-based multipath error correction for GPS differential phase. IEEE Trans. Aerosp. Electron. Syst., 32, 650660, https://doi.org/10.1109/7.489508.

Beşel C, Tanır Kayıkçı E (2021). Türkiye denizlerinde GNSS reflektometre tekniği ile deniz seviyesi değişiminin araștırılması. Jeodezi ve Jeoinformasyon Dergisi, 8(1),1-17. DOI: 10.9733/JGG.2021R0001.T
Chen Q, Won D \& Akos D M (2014). Snow depth sensing using the GPS L2C signal with a dipole antenna. EURASIP Journal on Advances in Signal Processing, 2014(1), 106, doi:10.1186/1687-6180-2014-106.

Chew C, Small E E \& Larson K M (2016). An algorithm for soil moisture estimation using GPS-interferometric reflectometry for bare and vegetated soil. GPS solutions, 20(3), 525-537, doi:10.1007/s10291-0150462-4

Gutmann E D, Larson K M, Williams MW, Nievinski F G \& Zavorotny V (2012). Snow measurement by GPS interferometric reflectometry: an evaluation at Niwot Ridge, Colorado. Hydrological Processes, 26(19), 2951-2961, doi:10.1002/hyp.8329.

Han M, Zhu Y, Yang D, Chang Q, Hong X, Song S (2020). Soil moisture monitoring using GNSS interference signal: proposing a signal reconstruction method. Remote Sens. Letters, 11(4), 373-382.DOI: 10.1080/2150704X.2020.1718235.

Hofmann-Wellenhof B, Lichtenegger H, Wasle E (2008). GNSS-global navigation satellite systems: GPS, GLONASS, Galileo, and more. Springer Science \& Business Media.

Jin S, Qian X, Kutoglu H (2016). Snow depth variations estimated from GPS-Reflectometry: A case study in Alaska from L2P SNR data. Remote sensing, 8(1), 63, doi:10.3390/rs8010063.

Larson K M, Löfgren J S \& Haas R (2013). Coastal sea level measurements using a single geodetic GPS receiver. Adv. Space Res., 51, 13011310, https://doi.org/10.1016/j.asr.2012.04.017.

Larson K M, Palo S, Roesler C, Mattia M, Bruno V, Coltelli M \& Fee D (2017). Detection of plumes at Redoubt and Etna volcanoes using the GPS SNR method. J. Volcanol. Geoth. Res. 344, 26-39, https://doi.org/10.1016/j.polar.2018.11.009.

Larson K M, Small E E, Gutmann E, Bilich P \& Axelrad J B (2008). Using GPS multipath to measure soil moisture fluctuations: initial results. GPS Solut. 12 (3), 173177. https://doi.org/10.1007/s10291-007-0076-6.

Larson K M, Braun J J, Small E E, Zavorotny V U, Gutmann E D, Bilich A L (2009a). GPS multipath and its relation to near-surface soil moisture content. IEEE Journal of Selected Topics in Applied Earth Observations and Remote Sensing, 3(1), 91-99, doi:10.1109/JSTARS.2009.2033612.

Larson K M, Gutmann E D, Zavorotny V U, Braun J J, Williams M W, Nievinski F G (2009b). Can we measure snow depth with GPS receivers? Geophysical Research Letters, 36(17), doi:10.1029/2009GL039430.

Lomb N R (1976). Least-squares frequency analysis of unequally spaced data. Astrophys. Space Sci., 39, 447462, https://doi.org/10.1007/BF00648343.

Martin-Neira M (1993). A passive reflectometry and interferometry system (PARIS): Application to ocean altimetry. ESA J. 17 (4), 331-355.

Neumann B, Vafeidis A, Zimmermann J \& Nicholls R (2015). Future coastal population growth and exposure to sea-level rise and coastal flooding-a global assessment. PLoS ONE 10(3):e0118571. https ://doi.org/10.1371/journ al.pone.01185 71 
Nievinski F G \& Larson K M (2014a). Inverse Modeling of GPS Multipath for Snow Depth Estimation-Part I: Formulation and Simulations. IEEE Trans. Geosci. Remote Sens. 52 (10), 6555-6563. https://doi.org/10.1109/TGRS.2013.2297681.

Nievinski F G \& Larson K M (2014b). Inverse Modeling of GPS Multipath for Snow Depth Estimation-Part II: Application and Validation. IEEE Trans. Geosci. Remote Sens. 52 (10), 6564-6573. https://doi.org/10.1109/TGRS.2013.2297688.

Ozeki M, Heki K (2012). GPS snow depth meter with geometry-free linear combinations of carrier phases. Journal of Geodesy, 86(3), 209-219, doi:10.1007/s00190-011-0511-x.

Qian X \& Jin S (2016). Estimation of snow depth from GLONASS SNR and phase-based multipath reflectometry. IEEE Journal of Selected Topics in Applied Earth Observations and Remote Sensing, 9(10), 4817-4823.

Rousseeuw P J \& Leroy A M (1987). Robust regression and outlier detection (Vol. 1). New York: Wiley.

Roussel N, Frappart F, Ramillien G, Darrozes J, Baup F, Lestarquit L, Ha M C (2016). Detection of soil moisture variations using GPS and GLONASS SNR data for elevation angles ranging from 2 to 70. IEEE Journal of Selected Topics in Applied Earth Observations and Remote Sensing, 9 (10), 4781-4794, doi:10.1109/JSTARS.2016.2537847.

Santamaría-Gómez A \& Watson C (2017). Remote leveling of tide gauges using GNSS reflectometry: Case study at Spring Bay, Australia. GPS Solutions, 21, 451459, https://doi.org/10.1007/s10291-016-0537-X.

Small E E, Larson K M \& Braun J J (2010). Sensing vegetation growth with reflected GPS signals. Geophys. Res. Lett. 37 (12), 245-269. https://doi.org/10.1029/2010GL042951.

Scargle J D (1982). Studies in astronomical time series analysis. II.Statistical aspects of spectral analysis of unevenly spaced data. Astrophys. J., 263, 835-853, https://doi.org/10.1086/160554.
Strandberg J, Hobiger T \& Haas R (2016). Improving GNSS-R sea level determination through inverse modeling of SNR data. Radio Science, 51(8), 12861296.

Strandberg J, Hobiger T \& Haas R (2019). Real-time sealevel monitoring using Kalman filtering of GNSS-R data. GPS Solut. 23 (3). https://doi.org/10.1007/s10291-019-0851-1.

Tabibi S, Geremia-Nievinski F \& van Dam T (2017). Statistical comparison and combination of GPS, GLONASS, and multi-GNSS multipath reflectometry applied to snow depth retrieval. IEEE Transactions on Geoscience and Remote Sensing, 55(7), 3773-3785.

Tunalıoğlu N, Doğan A H \& Durdağ U M (2019). GPS sinyal gürültü oranı verileri ile kar kalınlığının belirlenmesi. Jeodezi ve Jeoinformasyon Dergisi, 6(1) 1-9. Doi: 10.9733/JGG.2019R00601001.T.

Xi R, Zhou X, Jiang W, Chen Q (2018). Simultaneous estimation of dam displacements and reservoir level variation from GPS measurements. Meas., 122, 247 256, doi:10.1016/j.measurement.2018.03.036.

Wang X, Zhang Q, Zhang S (2018). Water levels measured with SNR using wavelet decomposition and LombScargle periodogram. GPS Solut 22, 22. https://doi.org/10.1007/s10291-017-0684-8

Williams S D, Bell P S, McCann D L, Cooke R \& Sams C (2020). Demonstrating the potential of low-cost GPS units for the remote measurement of tides and water levels using interferometric reflectometry. Journal of Atmospheric and Oceanic Technology, 37(10), 19251935.

Zhang S, Roussel N, Boniface K, Ha M C, Frappart F, Darrozes J, Baup F \& Calvet J C (2017). Use of reflected GNSS SNR data to retrieve either soil moisture or vegetation height from a wheat crop. Hydrol. Earth Syst. Sci., 21, 4767-4784, https://doi.org/10.5194/hess-21-4767-2017. 